See Article page XXX.

\section{Commentary: Early surgery should be pursued for all severe regurgitant lesions}

\author{
Alexander A. Brescia, MD, MSc, and \\ Steven F. Bolling, MD, on behalf of the Michigan \\ Mitral Research Group (MMRG)
}

Wang and colleagues ${ }^{1}$ performed a single-center retrospective analysis of patients undergoing isolated tricuspid valve surgery for tricuspid regurgitation (TR) performed by 17 surgeons between 2004 and 2018 to compare mortality in patients with class I indications (severe symptomatic TR, $\mathrm{n}=115$ ) versus earlier surgery (asymptomatic TR with right ventricular dilation and/or dysfunction, $n=44$ ). At a mean of 5 years, patients with class I indications, older patients, and those with diabetes were associated with higher mortality. These data led the authors to conclude that earlier surgery in patients with isolated TR may improve outcomes.

A key consideration in treating these patients and analyzing these data is patient selection. During a 15-year study period, 44 patients were selected to undergo surgery before meeting class I indications. Although these patients ultimately did better than those who became symptomatic, the challenge for surgeons is how to appropriately select these patients for early surgery and whether these findings are generalizable beyond Cleveland Clinic and other highvolume valve centers of excellence. While it may be reasonable to consider early surgery for asymptomatic patients with severe TR, referral centers may not see patients until they already meet class I indications. Alternatively, other centers may see candidates who are still asymptomatic, for whom surgery may be considered but do not necessarily reflect the group of 44 patients over 15 years analyzed in this study. Accordingly, these findings may not be generalizable.

\footnotetext{
From the Department of Cardiac Surgery, University of Michigan, Ann Arbor, Mich. Disclosures: The authors reported no conflicts of interest.

The Journal policy requires editors and reviewers to disclose conflicts of interest and to decline handling or reviewing manuscripts for which they may have a conflict of interest. The editors and reviewers of this article have no conflicts of interest.

Received for publication Sept 26, 2021; revisions received Sept 26, 2021; accepted for publication Sept 28, 2021.

Address for reprints: Alexander A. Brescia, MD, MSc, Department of Cardiac Surgery, Frankel Cardiovascular Center, University of Michigan, 1500 E. Medical Center Dr, Ann Arbor, MI 48109 (E-mail: abrescia@med.umich.edu).

J Thorac Cardiovasc Surg 2021; $\mathbf{\square}: 1-2$

$0022-5223 / \$ 36.00$

Copyright (c) 2021 by The American Association for Thoracic Surgery

https://doi.org/10.1016/j.jtcvs.2021.09.048
}

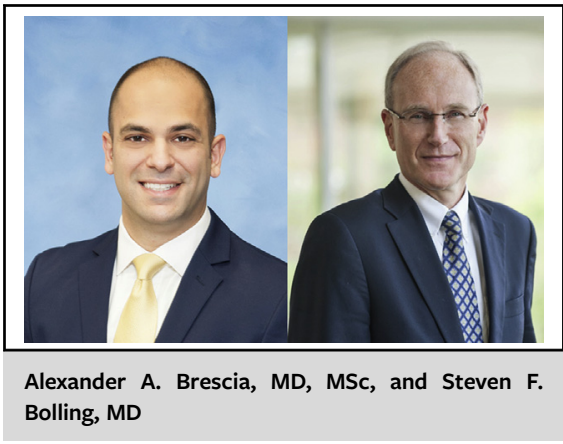

CENTRAL MESSAGE

Due to the infrequency of

tricuspid surgery, conclusions

from single-center studies are

limited. Nonetheless, it is

reasonable to consider early

surgery for patients with severe

regurgitation.

However, we feel it is always reasonable to consider early surgery for patients with any severe regurgitant lesion. Whereas existing data are sparse and difficult to generate in high numbers for tricuspid valve surgery, the question of early surgery has been addressed for asymptomatic severe mitral regurgitation. Since all regurgitant lesions end up worsening, early surgery for symptomatic, severe mitral regurgitation specifically while the ejection fraction remains $>60 \%$ has repeatedly been found to be beneficial. ${ }^{2-4}$

While this study addresses a thought-provoking clinical question, it remains difficult to draw any conclusions from the 44 patients undergoing early surgery performed by a total of 17 surgeons over a 15-year period. Since tricuspid surgery is so infrequent, larger databases may be more helpful in addressing the research question. Nonetheless, this contribution adds to a small body of literature on this topic, and we agree with the authors that early surgery should be pursued after considering the risks and benefits for each patient.

\section{References}

1. Wang TKM, Akyuz K, Xu B, Gillinov AM, Pettersson GB, Griffin BP, et al. Early surgery is associated with improved long-term survival compared to class I indication for isolated severe tricuspid regurgitation. J Thorac Cardiovasc Surg. July 30, 2021 [Epub ahead of print].

2. Suri RM, Vanoverschelde JL, Grigioni F, Schaff HV, Tribouilloy C, Avierinos JF, et al. Association between early surgical intervention vs watchful waiting and outcomes for mitral regurgitation due to flail mitral valve leaflets. JAMA. 2013;310: 609-16. 
3. Kang DH, Park SJ, Sun BJ, Cho EJ, Kim DH, Yun SC, et al. Early surgery versus conventional treatment for asymptomatic severe mitral regurgitation: a propensity analysis. J Am Coll Cardiol. 2014;63:2398-407.
4. Desai A, Thomas JD, Bonow RO, Kruse J, Andrei A-C, Cox JL, et al. Asymptomatic degenerative mitral regurgitation repair: validating guidelines for early intervention. J Thorac Cardiovasc Surg. 2021;161:981-94.e5. 